\title{
Probing endocytosis during the cell cycle with minimal experimental perturbation
}

Running title: Endocytosis along the cell cycle

\author{
António JM Santos ${ }^{1}$ and Emmanuel Boucrot ${ }^{2, \pi}$ \\ ${ }^{1}$ Cell and Developmental Biology Program, Centre for Genomic Regulation (CRG), Barcelona, Spain \\ ${ }^{2}$ Institute of Structural and Molecular Biology, University College London and Birkbeck, Gower Street, London WC1E 6BT, UK \\ " Correspondence to: e.boucrot@ucl.ac.uk
}

\begin{abstract}
Summary
Endocytosis mediates the cellular uptake of nutrients, modulates signaling by regulating levels of cell surface receptors and is usurped by pathogens during infection. Endocytosis activity is known to vary during the cell cycle, in particular during mitosis. Importantly, different experimental conditions can lead to opposite results and conclusions, thereby emphasizing the need for a careful design of protocols. For example, experiments using serum-starvation, ice-cold steps or using mitotic arrest produced by chemicals widely used to synchronize cells (nocodazole, RO-3306 or S-Trityl-L-cysteine) induce a blockage of clathrin-mediated endocytosis during mitosis not observed in unperturbed, dividing cells. In addition, perturbations produced by mRNA interference or dominant-negative mutant overexpression affect endocytosis long before cells are being assayed. Here, we describe simple experimental procedures to assay endocytosis along the cell cycle with minimal perturbations.
\end{abstract}

Key words: Endocytosis, clathrin-mediated endocytosis, cell cycle, mitosis, cell division, cell synchronization, serum starvation, pre-incubation on ice, nocodazole, RO-0336, S-Trityl-L-cysteine, siRNA, dynasore, pitstop, knock-sideways

\section{Introduction}

Endocytosis is essential to all eukaryotic cells for nutrient uptake and for controlling the levels of receptors, channels and transporters at their surface. There are several pathways of endocytosis defined by the receptors that use them, by their distinct morphological features or by their requirement of key cytosolic components (Doherty and McMahon 2009). Clathrin-mediated endocytosis (hereafter, CME) is the best characterized portal of entry into cells (McMahon and Boucrot 2011, Kirchhausen, Owen et al. 2014). By contrast, clathrin-independent endocytosis has been less well understood so far (Doherty and McMahon 2009, Maldonado-Baez, Williamson et al. 2013, Johannes, Parton et al. 2015).

Clathrin-coated pits are formed constitutively at the surface of cells upon polymerization of clathrin triskelia into lattices wrapping around the invaginating membrane. Receptors destined to be internalized (also called 'cargo' molecules) are sorted into clathrin-coated pits by various adaptor proteins as clathrin itself cannot bind to receptors or to membrane (McMahon and Boucrot 2011, Robinson 2015). The tetrameric adaptor complex AP2 is central to CME, forming an interaction hub 
between receptors, clathrin, lipids and associated adaptors proteins (McMahon and Boucrot 2011, Robinson 2015). Some cargoes, in particular transferrin and low-density lipoprotein (LDL) receptors, rely almost exclusively ( $>70-80 \%)$ on CME to enter cells and their rates of uptake are widely used as readout of the activity of the pathway (McMahon and Boucrot 2011). Another assay commonly used to measure CME is recording clathrin-coated pit and vesicle formation using live-cell imaging fluorescent microscopy (Kirchhausen 2009, Mettlen and Danuser 2014).

Inhibition of CME is best achieved in mammalian cells by gene silencing (RNA interference (RNAi) or knockout) of clathrin heavy chain or AP2 subunits using (Motley, Bright et al. 2003, Huang, Khvorova et al. 2004) or by sequestering them into the cytoplasm upon overexpression of high affinity binding protein domains, such as AP180 C-terminus (aa530-915) or Eps15 $\Delta 95 / 295$ mutants (Benmerah, Bayrou et al. 1999, Ford, Pearse et al. 2001). CME is also inhibited upon overexpression of Dynamin function-defective mutants such as K44A (Damke, Baba et al. 1994) or T65A (Marks, Stowell et al. 2001), although dynamin functions in other clathrin-independent endocytic pathways.

However, it is important to be mindful of the timeframe of the perturbations considering the biological process being studied. Endocytosis happens within minutes but gene silencing or mutant overexpression required several days to be efficient, thus CME will be measured well after the perturbation has began to occur. Thus, any phenotypes observed during the cell cycle stage studied might result from the compounded effect of the perturbations of endocytosis for many hours - or days - prior to the assay instead of a direct effect on CME.

Typically, RNAi requires at least 3 days for the levels of the protein of interest to decrease by $80-90 \%$ of control. RNA interference blocks translation of targeted proteins by degrading their mRNA, thereby blocking production of new protein. But the existing, original, pool of the protein of interest is still present in the cells. Its levels are gradually decreased by proteasome or lysosomal degradation (normal recycling of proteins) and by dilution upon cell division. Thus, assuming an optimal inhibition of mRNA translation of a very long-lived protein (such as clathrin heavy chain, which turnover rate is as long as the cell cycle), it takes theorically 3 cell divisions to dilute protein levels down to $\sim 12.5 \%$ of control levels (that is, $\sim 87.5 \%$ depletion) (Figure 1). But, by the time one assays the samples on day 3 , cells will have divided twice (during day 1 and 2 ) with $\sim 50 \%$ and $\sim 25 \%$ of initial protein levels, respectively. This decrease will induce defects that cumulated and that will contribute greatly to any phenotype observed during the assay.

Therefore it is desirable to minimize indirect adverse effects of the experimental protocols. Favourable options are to time the overexpression of dominant-negative mutants that its onset coincides with the cell cyle stage studied (as described below) or to use rapid (minutes) inactivation methods using small compound inhibitors such as Dynasore, Pitstop 2 (Macia, Ehrlich et al. 2006, von Kleist, Stahlschmidt et al. 2011), or acute protein sequestration, or 'knock-sideways' (Robinson, Sahlender et al. 2010).

Although widely used in many studies, some experimental conditions such as cold preincubation or serum starvation prior to ligand uptake affect their endocytosis (Boucrot, Saffarian et al. 2010). Historically used to artificially enhance endocytosis by upregulating receptor levels on the cell surface (serum starvation) or to synchronize entry (pre-incubation of cells with ligands on ice), these steps introduce bias into the experiments by affecting cell physiology and membrane biophysical properties. Serum starvation, usually performed for $16 \mathrm{~h}$ (overnight) prior to endocytic assays, activates autophagy within a few hours (Settembre, Di Malta et al. 2011), thereby changing the endo-lysosomal system of the cells to be assayed. Pre-incubation of cells with ligands on ice affects plasma membrane fluidity (likely inducing phase transition), and favors ligand cross-linking, which will impact endocytosis following warming up back to $37^{\circ} \mathrm{C}$. These experimental conditions were also reported to up-regulate clathrin-independent pathways, and thus affecting cell physiology. In addition, chemical synchronization used to stall cells at various stages of the cell cycle (serum starvation, double 
thymidine block, nocodazole, RO-3306 or S-Trityl-L-cysteine) also affect endocytosis (Boucrot and Kirchhausen 2007, Tacheva-Grigorova, Santos et al. 2013, Aguet, Upadhyayula et al. 2016). This chapter outlines methods that we used to measure endocytosis along the cell cycle with minimal experimental perturbations.

\section{Materials}

1 Primary, normal cells or cell lines cultured in their appropriate complete growth medium (see Note 1).

2 Treatments being investigated (inhibitor drugs, siRNA, plasmids etc.). Here, we provide guidance for the use of chemical CME inhibitors (Pitstop2 (25 mM stock in DMSO), Dynasore (80 mM stock in DMSO) or Dyngo-4a (10 mM stock in DMSO)) and overexpressed inhibitory proteins (AP180 C-terminus (aa530-915) and Eps15 $\Delta 95 / 295$, and functiondefective mutants such as Dynamin K44A or T65A)

3 Phosphate-buffered saline (PBS) buffer: $138 \mathrm{mM} \mathrm{NaCl}, 2.7 \mathrm{mM} \mathrm{KCl}, 10 \mathrm{mM} \mathrm{Na}_{2} \mathrm{HPO}_{4}$, $1.76 \mathrm{mM} \mathrm{KH}_{2} \mathrm{PO}_{4}$ equilibrated at $\mathrm{pH}$ 7.4.

$4 \quad$ EDTA-based cell detachment solution: 0.4 mM EDTA in PBS without $\mathrm{Ca}^{2+}$ and $\mathrm{Mg}^{2+}$.

5 Transfection reagent as appropriate for the cell type used (e.g. Lipofectamine 2000, Thermo Scientific).

6 Fluorescently-labelled ligands to monitor endocytosis (e.g. Alexa488-Transferrin, Thermo Scientific).

$7 \quad$ Stripping buffer $1(\mathrm{pH} 5.5): 150 \mathrm{mM} \mathrm{NaCl}, 20 \mathrm{mM}$ HEPES, 5mM KCl, $1 \mathrm{mM} \mathrm{CaCl}{ }_{2}, 1 \mathrm{mM}$ $\mathrm{MgCl}_{2}$, adjusted to $\mathrm{pH} 5.5$.

$8 \quad$ Stripping buffer $2(\mathrm{pH} 2.5): 150 \mathrm{mM} \mathrm{NaCl}, 0.2 \mathrm{M}$ acetic acid, $5 \mathrm{mM} \mathrm{KCl}, 1 \mathrm{mM} \mathrm{CaCl}{ }_{2}, 1 \mathrm{mM}$ $\mathrm{MgCl}_{2}$, adjusted to $\mathrm{pH} 2.5$.

$9 \quad$ Paraformaldehyde (PFA), diluted to $3.7 \%$ in PBS.

$10 \quad 50 \mathrm{mM} \mathrm{NH}_{4} \mathrm{Cl}$ in PBS

11 Ligand/antibody uptake assay medium: $\alpha$-MEM without phenol red supplemented with $20 \mathrm{mM}$ Hepes, pH 7.2.

Imaging medium: $\alpha$-MEM without phenol red supplemented with $20 \mathrm{mM}$ Hepes, $\mathrm{pH} 7.2$ and $5 \%$ FBS)

\section{Methods}

\subsection{Optimisation of cell cycle without drug synchronisation}

Upon confluency, cells terminate their current cell cycle and naturally pause in early G1 (Coupin, Muller et al. 1999). After several hours following contact, normal (i.e. untransformed) cells exit the cell 
cycle to become quiescent (known as the G0 stage of the cell cycle) (Coller, Sang et al. 2006). Transformed cells having lost contact inhibition stall first in their cell cycle in early G1 upon reaching confluency (Figure 2a-b), but after several hours, can extravasate to continue into another cell cycle. Thus, one can take advantage of the initial, contact-induced, stalling of both normal and transformed cells in early G1 to time cell cultures. When cells are passaged few hours after reaching confluency, a greater proportion will resume their cell cycle at the same stage (early G1) and an increased proportion (up to $50 \%$ increase) of cells will concomitantly reach S, G2 and M phases (Figure 2c) than in cultures growing exponentially (and thus asynchronously) (Coupin, Muller et al. 1999, Boucrot and Kirchhausen 2007, Boucrot, Howes et al. 2011).

This simple procedure takes advantage of the natural pause following cell-cell contact (Figure 2c), and provides an opportunity to naturally enrich cell cultures at each stage of the cell cycle. This requires that the experimenter knows the cell cycle length of cell type used for the assays. This is determined using classic cell doubling time measurements and flow cytometry cell cycle analysis (Figure 2a). In our experience, it varies between 14 to $28 \mathrm{~h}$ between cell types.

1. Grow cells to become fully confluent for $\sim 24$ h (see Note 2 ).

2. Detach cells using EDTA-based cell detachment solution (see Note 3).

3. Seed cells at $\sim 70 \%$ confluence in their appropriate complete culture medium (see Note 4).

G1 phase: After $\sim 30 \%$ of the cell cycle length ( $\sim 8 \mathrm{~h}$ for a $24 \mathrm{~h}$ cell cycle, Figure $2 \mathbf{b}-\mathbf{c})$, over $90 \%$ of cells should be in G1, as compared to 50-70\% in asynchronized populations (see Note 5).

S phase: After $\sim 70 \%$ of the cell cycle length $(\sim 17 \mathrm{~h}$ for a $24 \mathrm{~h}$ cell cycle, Figure $2 \mathbf{b}-\mathbf{c})$, the majority of cells should be in S, as compared to $15-20 \%$ in asynchronized populations (see Note 6).

G2 phase: After $\sim 90 \%$ of the cell cycle length ( $21 \mathrm{~h}$ for a $24 \mathrm{~h}$ cell cycle, Figure $2 \mathbf{b}-\mathbf{c})$, the majority of cells should be in G2, as compared to $15-20 \%$ in asynchronized populations (see Note 7).

M phase: after $\sim 100 \%$ of the cell cycle length ( $24 \mathrm{~h}$ for a $24 \mathrm{~h}$ cell cycle, Figure $2 \mathbf{b}-\mathbf{c})$, there is a wave of cells naturally undergoing mitosis lasting 2 to $3 \mathrm{~h}$. During this time window, the mitotic index (\% of cell undoing mitosis) can be up to $30 \%$, as compared to $1-5 \%$ in asynchronized populations (see Note 8).

\subsection{Inhibiting CME at specific cell cycle stages using mutant protein overexpression}

Clathrin-mediated endocytosis is inhibited by overexpressing protein fragments that sequester clathrin or AP2 in the cytoplasm (AP180 C-terminus (aa530-915) and Eps15 $495 / 295$, respectively (Benmerah, Bayrou et al. 1999, Ford, Pearse et al. 2001) or function-defective mutants such as Dynamin K44A (Damke, Baba et al. 1994) or T65A (Marks, Stowell et al. 2001). (see Note 8)

1. On test samples, determine the minimal time after transfection after which the construct is expressed. Fast-folding proteins are expressed as soon as $\sim 8 \mathrm{~h}$ after transfection, whereas slow maturing ones require over 24h (see Note 9).

2. Passage and transfect cells for the appropriate number of hours prior to the assay (see Figure 3a). For example, using a protein expressing $10 \mathrm{~h}$ after transfection and a cell line having a $24 \mathrm{~h}$ cell cycle, time the passaging and transfection as follow: 
G1 phase: Transfect cells just after plating (also called 'reverse transfection', when the cells are still suspended). After $\sim 10 \mathrm{~h}$, most transfected cells will be in G1 (Figure 3a).

$\underline{\mathrm{S} \text { phase: }}$ Plate the cells as in 3.1. Transfect cells $\sim 7 \mathrm{~h}$ after plating. After $\sim 10 \mathrm{~h}$ (thus $\sim 17 \mathrm{~h}$ after cell plating) most transfected cells will be in S (Figure 3a ).

G2 phase: Plate the cells as in 3.1. Transfect cells $\sim 11 \mathrm{~h}$ after plating. After $\sim 10 \mathrm{~h}$ (thus $\sim 21 \mathrm{~h}$ after cell plating) most transfected cells will be in G2 (Figure 3a ).

M phase: Plate the cells as in 3.1. Transfect cells $\sim 14 \mathrm{~h}$ after plating. After $\sim 10 \mathrm{~h}$ (thus $\sim 24 \mathrm{~h}$ after cell plating) most transfected cells will be in mitosis (Figure 3a). For a transfection efficiency of $\sim 30 \%$, and a mitotic index of $\sim 30 \%$, one can expect $\sim 10 \%$ of all cells to be transfected and undergoing mitosis at the time of the assay (see Note 10).

\subsection{Inhibiting CME at specific cell cycle stages using small molecule inhibitors}

Using the cell seeding procedure detailed in 3.1, treat cell cultures in G1, S, G2 or M phase with the appropriate small inhibitors for the appropriate time before the assays (Figure $\mathbf{3 b}$ ).

Dynamin inhibitors: dilute the inhibitor to the appropriate concentration into culture medium (Dynasore: $80 \mu \mathrm{M}$, Dyngo-4a: $10 \mu \mathrm{M}$ (Macia, Ehrlich et al. 2006, McCluskey, Daniel et al. 2013). Replace culture medium with medium containing the inhibitor and incubate at $37{ }^{\circ} \mathrm{C}$ for the appropriated time (a minimum of $10 \mathrm{~min}$ and maximum of $60 \mathrm{~min}$ is recommended) (see Note 11).

Clathrin inhibitors: dilute the inhibitor to the appropriate concentration into culture medium (Pitstop 2: $50 \mu \mathrm{M}$ (von Kleist, Stahlschmidt et al. 2011)). Replace the culture medium with the medium containing the inhibitor and incubate at $37{ }^{\circ} \mathrm{C}$ for the appropriate time (a minimum of $10 \mathrm{~min}$ and maximum of $60 \mathrm{~min}$ is recommended) (see Note 12).

\subsection{Fluorescently-tagged ligand uptake endocytic assays in unperturbed cells}

Although widely used in the literature, cold pre-incubation or serum starvation prior to ligand uptake both affect their endocytosis (Boucrot, Saffarian et al. 2010). To minimize experimental perturbations, the following assays use direct incubation of ligands or antibodies.

Cells seeded on glass coverslips or glass-bottom microplates should be prepared according to 3.1 and 3.2 , as required, prior to the assay.

1 Pre-warm $\left(37^{\circ} \mathrm{C}\right.$ for $\left.1 \mathrm{~h}\right)$ ligand uptake assay medium (see Note $\left.\mathbf{1 3}\right)$.

2 Dilute fluorescently-tagged ligand to the desired concentration (for example, $50 \mu \mathrm{g} / \mathrm{ml}$ Tf-Alexa-488) in warmed ligand uptake assay medium

3 Take cells out of the incubator, swiftly aspirate culture medium and replace it with pre-warmed assay medium containing ligand, return the cells to the $37^{\circ} \mathrm{C}$ incubator and start a timer (see Note 14).

4 After desired time has elapsed, remove the cells from the incubator, aspirate assay medium, add icecold PBS and place the cells on a water-ice tray (see Note 15). 
5 Wash the cells another time with ice-cold PBS, and incubate them on ice with stripping buffer 1 for 5 min (see Note 16).

6 Remove stripping buffer 1 and replace with fresh ice-cold stripping buffer 1 and incubate for another 5 min on ice.

7 Wash the cells three times with ice-cold PBS (see Note 17).

8 Add fixative solution (3.7\% PFA in PBS) and incubate on ice for $20 \mathrm{~min}$.

9 Wash the fixed cells three times with PBS containing $50 \mathrm{mM} \mathrm{NH}_{4} \mathrm{Cl}$ (see Note 18).

10 Immunostain cells as required (see Note 19).

\subsection{Antibody uptake feeding assays}

Cells seeded on glass coverslips or glass-bottom microplates should be prepared according to 3.1 and 3.2 , as required, prior to the assay.

1 Pre-warm $\left(37^{\circ} \mathrm{C}\right.$ for $\left.1 \mathrm{~h}\right)$ antibody uptake assay medium (see Note 13 ).

2 Dilute antibody to the desired concentration (for example, $5 \mu \mathrm{g} / \mathrm{ml}$ for an antibody against the ectodomain of EGFR).

3 Take cells out of the incubator, swiftly aspirate culture medium and replace it with pre-warmed assay medium containing antibodies, return the cells to the $37^{\circ} \mathrm{C}$ incubator and start a timer. (see Note 14).

4 After the desired time has elapsed, remove the cells from the incubator, aspirate assay medium, add ice-cold PBS and place the cells on a water-ice tray (see Note 15).

5 Wash the cells another time with ice-cold PBS, and incubate them on ice with stripping buffer 2 for 5 $\min ($ see Note 20).

6 Remove stripping buffer 2 and replace it with fresh ice-cold stripping buffer 2 and incubate for another $5 \mathrm{~min}$.

7 Wash the cells three times with ice-cold PBS (see Note 17).

8 Add fixative solution (3.7\% PFA in PBS) and incubate on ice for $20 \mathrm{~min}$.

9 Wash the fixed cells three times with PBS containing 50mM NH $4 \mathrm{Cl}$ (see Note 18).

10 Immunostain cells as required (see Note 21).

\section{6 spatio-temporal measurements of clathrin-coated pits and vesicles formation}

Gene-edited cells or cells stably expressing EGFP-tagged AP2 (б2-EGFP (Ehrlich, Boll et al. 2004) or EGFP- $\alpha 2$ (Rappoport and Simon 2008)) or clathrin (EGFP-CLCa (Gaidarov, Santini et al. 1999)) should be seeded on glass-bottom dishes or microplates and prepared according to 3.1 and 3.2 , as required, prior to the assay. 
1 Pre-warm $\left(37^{\circ} \mathrm{C}\right.$ for $\left.1 \mathrm{~h}\right)$ imaging medium (see Note 22).

2 Replace culture medium with imaging medium.

3 Image clathrin-coated pit and vesicle formation using a spinning-disc confocal (Ehrlich, Boll et al. 2004), a total-internal reflection (TIRF) (Merrifield, Feldman et al. 2002) or a light-sheet (Aguet, Upadhyayula et al. 2016) microscope equipped with a $37^{\circ} \mathrm{C}$ a $5 \% \mathrm{CO}_{2}$ incubation chamber (see Note 23).

4 Quantify clathrin-coated pit and vesicle formation using automated tracking softwares (eg. (Jaqaman, Loerke et al. 2008)).

\section{Notes}

1. A wide variety of cells may be used. The methods described here use human normal, diploid hTERT-RPE1 cells, but are easily adapted for other cell types.

2. About $24 \mathrm{~h}$ after cell confluency is required to induce contact inhibition of growth (Coupin, Muller et al. 1999, Coller, Sang et al. 2006).

3. The timings presented in 3.1 were set up using cells detached upon calcium chelation (EDTA-based cell detachment). Detaching cells with trypsin-based solutions will likely require longer times as it shaves cells from a significant proportion of their cell surface integrins and thus slows reattachment onto the substratum.

4. We found that seeding cells at this confluency was required for a re-entry into the cell cycle following the timeframes presented. Seeding cells at lower density decreases the proportion of cells at each stage of the cell cycle after the respective timeframes presented in 3.1

5. The proportion of cells actually in G1 should be confirmed using flow cytometry (proportion of ' $2 \mathrm{n}$ ' cells).

6. The proportion of cells actually in S should be confirmed using flow cytometry.

7. The proportion of cells actually in G2 should be confirmed using flow cytometry.

8. Mitotic sub-stages (prophase, metaphase, anaphase, telophase and cytokinesis) can be easily distinguished using bright-field or phase contrast microscopy.

9. Choosing the minimum time following transfection after which the mutant protein is expressed is crucial to minimize indirect effects of blocking endocytosis for long periods of time before the cell cycle of interest.

10. This procedure generates a low number of transfected cells undergoing mitosis $(\sim 10 \%)$ but singlecell approaches (microscopy or flow cytometry) can easily identify them.

11. Other Dynamin inhibitors such as Dynole 34-2, OctMAB, MitMAB, Rhodadyn C10 or Iminodyn22 (Quan, McGeachie et al. 2007, Hill, Gordon et al. 2009, Robertson, Hadzic et al. 2012) can be used as well.

12. Other chemical inhibitions of $\mathrm{CME}$ such as hypertonic shock ( $0.45 \mathrm{M}$ sucrose), potassium depletion, monodansylcadaverine, chlorpromazine or phenylarsine oxide (Schlegel, Dickson et al. 
1982, Larkin, Brown et al. 1983, Gibson, Noel et al. 1989, Heuser and Anderson 1989, Wang, Rothberg et al. 1993), even though widely used in the literature are not recommended as they affect clathrin-independent endocytosis as well (Boucrot, Ferreira et al. 2015).

13. Pre-warming ligand/antibody uptake medium is required to maintain the temperature of the cells as close to $37^{\circ} \mathrm{C}$ as possible throughout the assay.

14. Incubations times can vary from $1 \mathrm{~min}$ to $60 \mathrm{~min}$, as required. To measure endocytic rates, several lengths of incubations must be measured.

15. The use of cold temperatures at the end of the assay is appropriate as the cells will be soon fixed. Adding ice-cold PBS stops any trafficking within seconds. Using ice + water mix to cool the plates/dishes during the subsequent steps insure a better temperature exchange and cooling than using ice only.

16. Washes with a mildly acidic stripping buffer ('Stripping buffer 1', $\mathrm{pH}$ 5.5) remove cell surface ligands that were not internalized after incubation.

17. Washes with PBS are required for raising back the $\mathrm{pH}$ to 7.4 after washes with stripping buffers.

18. Washes with $50 \mathrm{mM} \mathrm{NH}_{4} \mathrm{Cl}$ in $\mathrm{PBS}$ are required to inactivate any residual reactive PFA.

19. Counterstaining of protein(s) of interest, DNA (using DAPI or DRAQ5) and/or actin cytoskeleton (phalloidin) using other fluorophores than those coupled on the internalised ligand can be considered.

20. Washes with an acidic stripping buffer ('Striping buffer 2', $\mathrm{pH} 2.5$ ) remove cell surface antibodies that were not internalized after incubation. Note that cell surface stripping of antibodies requires lower $\mathrm{pH}$ than for endocytic ligands.

21. Fluorescently-labeled secondary antibodies towards the specie of internalized antibodies must be included in the immunostaining procedure (e.g. Alexa-488 coupled Goat anti-Rabbit secondary antibodies to label Rabbit anti-EGFR antibodies internalized during the feeding assay)

22. Pre-warming imaging medium is required to maintain the temperature of the cells as close to $37 \mathrm{C}$ as possible throughout the assay and to maintain clathrin-coated pits and vesicles dynamics.

23. Clathrin-coated pit and vesicle formation in mitotic cells can be imaged on the bottom surface (contacting the glass coverslip) using TIRF microscopy, both on the top or bottom surfaces using spinning-disk confocal microcopy or throughout entire cells using light-sheet super-resolution microscopy (Merrifield, Feldman et al. 2002, Ehrlich, Boll et al. 2004, Aguet, Upadhyayula et al. 2016).

\section{Acknowledgements}

A.J.M.S. was supported by Fundação para a Ciência e Tecnologia (SFRH / BD / 33545 / 2008) and E.B. was a Biotechnology and Biological Sciences Research Council (BBSRC) David Phillips Research Fellow. 


\section{Figure legends}

Figure 1: Protein dilution by cell division during RNA interference. Assuming an optimal inhibition of mRNA translation of a very long-lived protein, it takes theorically 3 cell divisions to dilute the existing protein levels down to $\sim 12.5 \%$ of control levels (that is, $\sim 87.5 \%$ depletion).

Figure 2: Optimisation of cell cycle without drug synchronization. (a) DNA profile of an asynchronous RPE1 cell population. DNA was labelled using Hoescht 33342. '2n' DNA peak correspond to cells in G1, '4n' DNA peak corresponds to cells in G2 or M and cells having between '2n' and '4n' DNA are ongoing S phase. (b) Percentage of cells at each cell of the cell cycle calculated from a DNA profile as in a for a cell type having a $24 \mathrm{~h}$ cell cycle (measured population doubling time). Natural contact inhibition period (early G1) in confluent cells is indicated in red. (c) Cell plating protocol to increase the percentage of cells in G1, S, G2 or M, respectively.

Figure 3: Inhibiting $\mathrm{CME}$ at specific cell cycle stages using mutant protein overexpression or small inhibitors. (a) Cell plating and transfection protocol to inhibit CME in cells in G1, S, G2 or M, respectively. (b) Cell plating and small inhibitor addition protocol to inhibit $\mathrm{CME}$ in cells in $\mathrm{G} 1, \mathrm{~S}, \mathrm{G} 2$ or $\mathrm{M}$, respectively.

\section{References}

Aguet, F., S. Upadhyayula, R. Gaudin, Y. Y. Chou, E. Cocucci, K. He, B. C. Chen, K. Mosaliganti, M. Pasham, W. Skillern, W. R. Legant, T. L. Liu, G. Findlay, E. Marino, G. Danuser, S. Megason, E. Betzig and T. Kirchhausen (2016). "Membrane dynamics of dividing cells imaged by lattice light-sheet microscopy." Mol Biol Cell.

Benmerah, A., M. Bayrou, N. Cerf-Bensussan and A. Dautry-Varsat (1999). "Inhibition of clathrincoated pit assembly by an Eps15 mutant." J Cell Sci 112 ( Pt 9): 1303-1311.

Boucrot, E., A. P. Ferreira, L. Almeida-Souza, S. Debard S., Y. Vallis, G. Howard, L. Bertot, N. Sauvonnet and H. T. McMahon (2015). "Endophilin marks and controls a clathrin-independent pathway of endocytosis." Nature 517(7535: 460-465

Boucrot, E., M. T. Howes, T. Kirchhausen and R. G. Parton (2011). "Redistribution of caveolae during mitosis." Journal of cell science 124(Pt 12): 1965-1972.

Boucrot, E. and T. Kirchhausen (2007). "Endosomal recycling controls plasma membrane area during mitosis." Proc Natl Acad Sci U S A 104(19): 7939-7944.

Boucrot, E., S. Saffarian, R. Zhang and T. Kirchhausen (2010). "Roles of AP-2 in clathrin-mediated endocytosis." PloS one 5(5): e10597.

Coller, H. A., L. Sang and J. M. Roberts (2006). "A new description of cellular quiescence." PLoS Biol 4(3): e83.

Coupin, G. T., C. D. Muller, A. Remy-Kristensen and J. G. Kuhry (1999). "Cell surface membrane homeostasis and intracellular membrane traffic balance in mouse L929 cells." J Cell Sci 112 ( Pt 14): 2431-2440.

Damke, H., T. Baba, D. E. Warnock and S. L. Schmid (1994). "Induction of mutant dynamin specifically blocks endocytic coated vesicle formation." J Cell Biol 127(4): 915-934. 
Doherty, G. J. and H. T. McMahon (2009). "Mechanisms of endocytosis." Annual review of biochemistry 78: 857-902.

Ehrlich, M., W. Boll, A. Van Oijen, R. Hariharan, K. Chandran, M. L. Nibert and T. Kirchhausen (2004). "Endocytosis by random initiation and stabilization of clathrin-coated pits." Cell 118(5): 591605 .

Ford, M. G., B. M. Pearse, M. K. Higgins, Y. Vallis, D. J. Owen, A. Gibson, C. R. Hopkins, P. R. Evans and H. T. McMahon (2001). "Simultaneous binding of PtdIns(4,5)P2 and clathrin by AP180 in the nucleation of clathrin lattices on membranes." Science 291(5506): 1051-1055.

Gaidarov, I., F. Santini, R. A. Warren and J. H. Keen (1999). "Spatial control of coated-pit dynamics in living cells." Nat Cell Biol 1(1): 1-7.

Gibson, A. E., R. J. Noel, J. T. Herlihy and W. F. Ward (1989). "Phenylarsine oxide inhibition of endocytosis: effects on asialofetuin internalization." Am J Physiol 257(2 Pt 1): C182-184.

Heuser, J. E. and R. G. Anderson (1989). "Hypertonic media inhibit receptor-mediated endocytosis by blocking clathrin-coated pit formation." J Cell Biol 108(2): 389-400.

Hill, T. A., C. P. Gordon, A. B. McGeachie, B. Venn-Brown, L. R. Odell, N. Chau, A. Quan, A. Mariana, J. A. Sakoff, M. Chircop, P. J. Robinson and A. McCluskey (2009). "Inhibition of dynamin mediated endocytosis by the dynoles--synthesis and functional activity of a family of indoles." J Med Chem 52(12): 3762-3773.

Huang, F., A. Khvorova, W. Marshall and A. Sorkin (2004). "Analysis of clathrin-mediated endocytosis of epidermal growth factor receptor by RNA interference." J Biol Chem 279(16): 1665716661 .

Jaqaman, K., D. Loerke, M. Mettlen, H. Kuwata, S. Grinstein, S. L. Schmid and G. Danuser (2008). "Robust single-particle tracking in live-cell time-lapse sequences." Nat Methods 5(8): 695-702.

Johannes, L., R. G. Parton, P. Bassereau and S. Mayor (2015). "Building endocytic pits without clathrin." Nat Rev Mol Cell Biol.

Kirchhausen, T. (2009). "Imaging endocytic clathrin structures in living cells." Trends Cell Biol 19(11): 596-605.

Kirchhausen, T., D. Owen and S. C. Harrison (2014). "Molecular structure, function, and dynamics of clathrin-mediated membrane traffic." Cold Spring Harb Perspect Biol 6(5): a016725.

Larkin, J. M., M. S. Brown, J. L. Goldstein and R. G. Anderson (1983). "Depletion of intracellular potassium arrests coated pit formation and receptor-mediated endocytosis in fibroblasts." Cell 33(1): 273-285.

Macia, E., M. Ehrlich, R. Massol, E. Boucrot, C. Brunner and T. Kirchhausen (2006). "Dynasore, a cell-permeable inhibitor of dynamin." Developmental cell 10(6): 839-850.

Maldonado-Baez, L., C. Williamson and J. G. Donaldson (2013). "Clathrin-independent endocytosis: a cargo-centric view." Exp Cell Res 319(18): 2759-2769.

Marks, B., M. H. Stowell, Y. Vallis, I. G. Mills, A. Gibson, C. R. Hopkins and H. T. McMahon (2001). "GTPase activity of dynamin and resulting conformation change are essential for endocytosis." Nature 410(6825): 231-235.

McCluskey, A., J. A. Daniel, G. Hadzic, N. Chau, E. L. Clayton, A. Mariana, A. Whiting, N. N. Gorgani, J. Lloyd, A. Quan, L. Moshkanbaryans, S. Krishnan, S. Perera, M. Chircop, L. von Kleist, A. B. McGeachie, M. T. Howes, R. G. Parton, M. Campbell, J. A. Sakoff, X. Wang, J. Y. Sun, M. J. Robertson, F. M. Deane, T. H. Nguyen, F. A. Meunier, M. A. Cousin and P. J. Robinson (2013). 
"Building a better dynasore: the dyngo compounds potently inhibit dynamin and endocytosis." Traffic 14(12): 1272-1289.

McMahon, H. T. and E. Boucrot (2011). "Molecular mechanism and physiological functions of clathrin-mediated endocytosis." Nature reviews. Molecular cell biology 12(8): 517-533.

Merrifield, C. J., M. E. Feldman, L. Wan and W. Almers (2002). "Imaging actin and dynamin recruitment during invagination of single clathrin-coated pits." Nat Cell Biol 4(9): 691-698.

Mettlen, M. and G. Danuser (2014). "Imaging and modeling the dynamics of clathrin-mediated endocytosis." Cold Spring Harb Perspect Biol 6(12): a017038.

Motley, A., N. A. Bright, M. N. Seaman and M. S. Robinson (2003). "Clathrin-mediated endocytosis in AP-2-depleted cells." The Journal of cell biology 162(5): 909-918.

Quan, A., A. B. McGeachie, D. J. Keating, E. M. van Dam, J. Rusak, N. Chau, C. S. Malladi, C. Chen, A. McCluskey, M. A. Cousin and P. J. Robinson (2007). "Myristyl trimethyl ammonium bromide and octadecyl trimethyl ammonium bromide are surface-active small molecule dynamin inhibitors that block endocytosis mediated by dynamin I or dynamin II." Mol Pharmacol 72(6): 1425-1439.

Rappoport, J. Z. and S. M. Simon (2008). "A functional GFP fusion for imaging clathrin-mediated endocytosis." Traffic 9(8): 1250-1255.

Robertson, M. J., G. Hadzic, J. Ambrus, D. Y. Pome, E. Hyde, A. Whiting, A. Mariana, L. von Kleist, N. Chau, V. Haucke, P. J. Robinson and A. McCluskey (2012). "The Rhodadyns, a New Class of Small Molecule Inhibitors of Dynamin GTPase Activity." ACS Med Chem Lett 3(5): 352-356.

Robinson, M. S. (2015). "Forty Years of Clathrin-coated Vesicles." Traffic 16(12): 1210-1238. Robinson, M. S., D. A. Sahlender and S. D. Foster (2010). "Rapid inactivation of proteins by rapamycin-induced rerouting to mitochondria." Dev Cell 18(2): 324-331.

Schlegel, R., R. B. Dickson, M. C. Willingham and I. H. Pastan (1982). "Amantadine and dansylcadaverine inhibit vesicular stomatitis virus uptake and receptor-mediated endocytosis of alpha 2-macroglobulin." Proc Natl Acad Sci U S A 79(7): 2291-2295.

Settembre, C., C. Di Malta, V. A. Polito, M. Garcia Arencibia, F. Vetrini, S. Erdin, S. U. Erdin, T. Huynh, D. Medina, P. Colella, M. Sardiello, D. C. Rubinsztein and A. Ballabio (2011). "TFEB links autophagy to lysosomal biogenesis." Science 332(6036): 1429-1433.

Tacheva-Grigorova, S. K., A. J. Santos, E. Boucrot and T. Kirchhausen (2013). "Clathrin-mediated endocytosis persists during unperturbed mitosis." Cell Rep 4(4): 659-668.

von Kleist, L., W. Stahlschmidt, H. Bulut, K. Gromova, D. Puchkov, M. J. Robertson, K. A. MacGregor, N. Tomilin, A. Pechstein, N. Chau, M. Chircop, J. Sakoff, J. P. von Kries, W. Saenger, H. G. Krausslich, O. Shupliakov, P. J. Robinson, A. McCluskey and V. Haucke (2011). "Role of the clathrin terminal domain in regulating coated pit dynamics revealed by small molecule inhibition." Cell 146(3): 471-484.

Wang, L. H., K. G. Rothberg and R. G. Anderson (1993). "Mis-assembly of clathrin lattices on endosomes reveals a regulatory switch for coated pit formation." J Cell Biol 123(5): 1107-1117. 


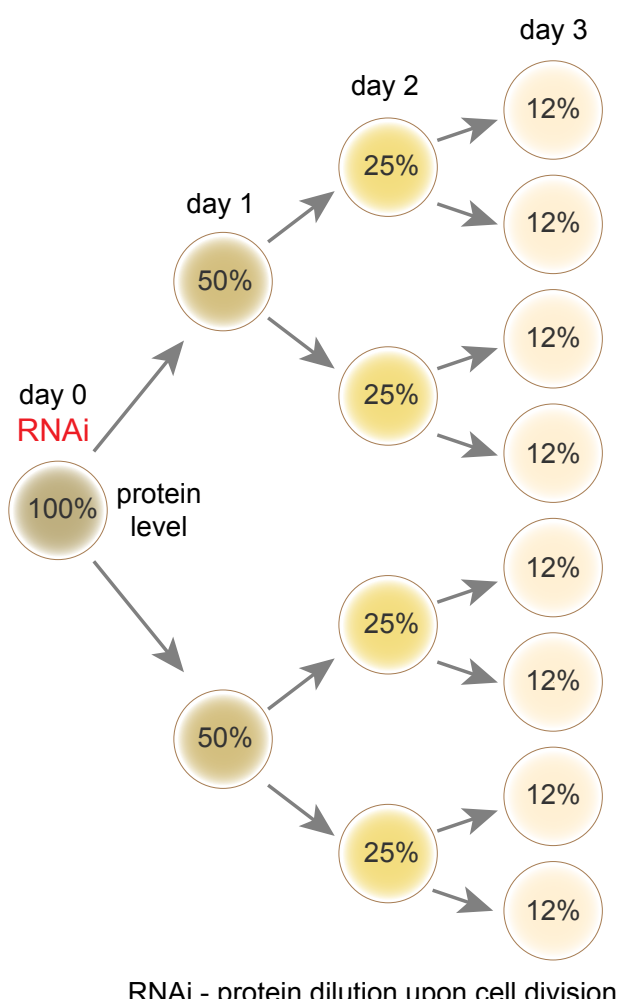

Figure 1 
a DNA profile (asynchronous cell population)

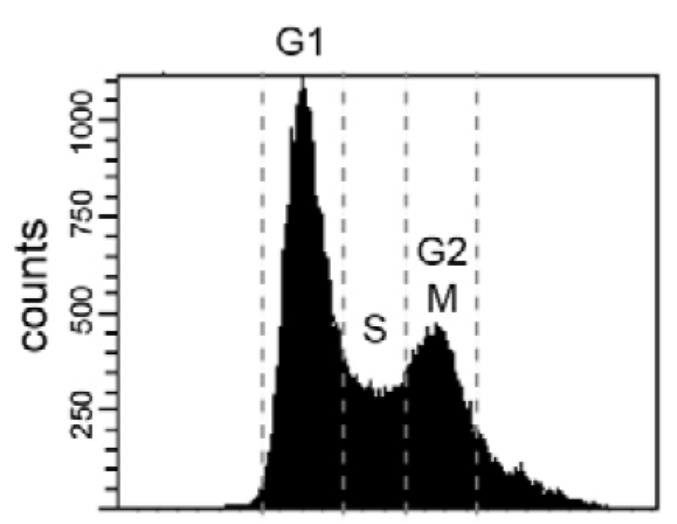

DNA

b Percentage of cells at each stage of the cell cycle (asynchronous cell population, 24h cell cycle)

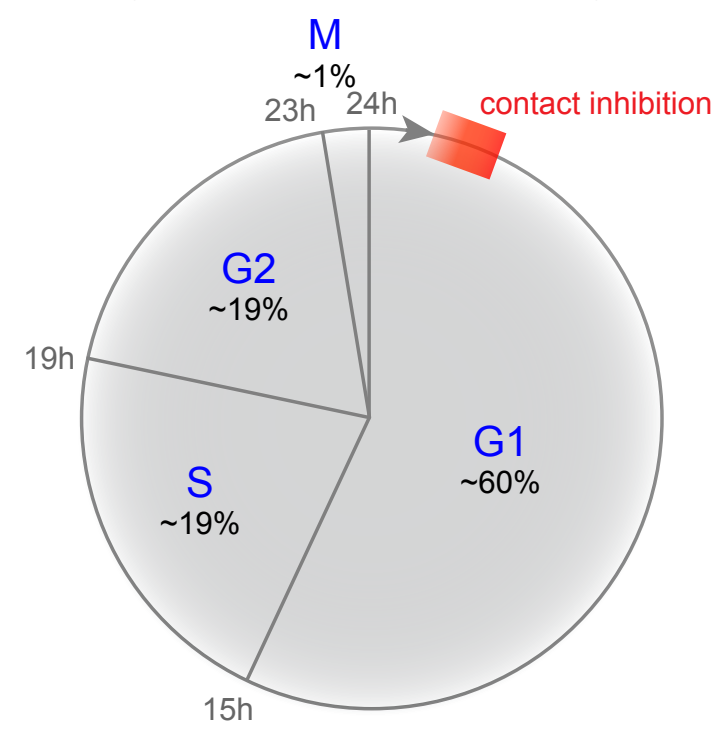

c
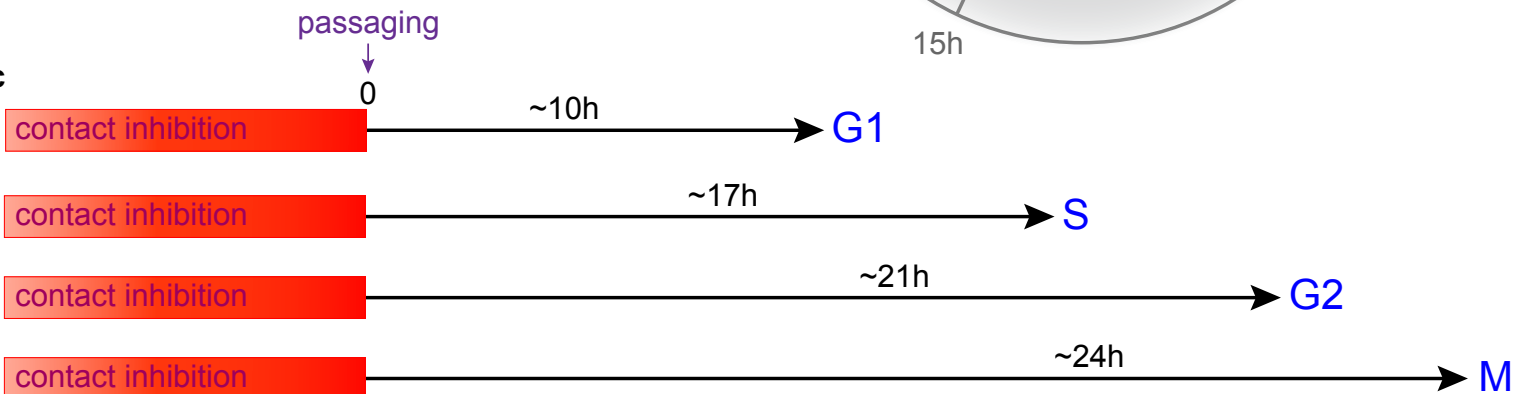

Figure 2 

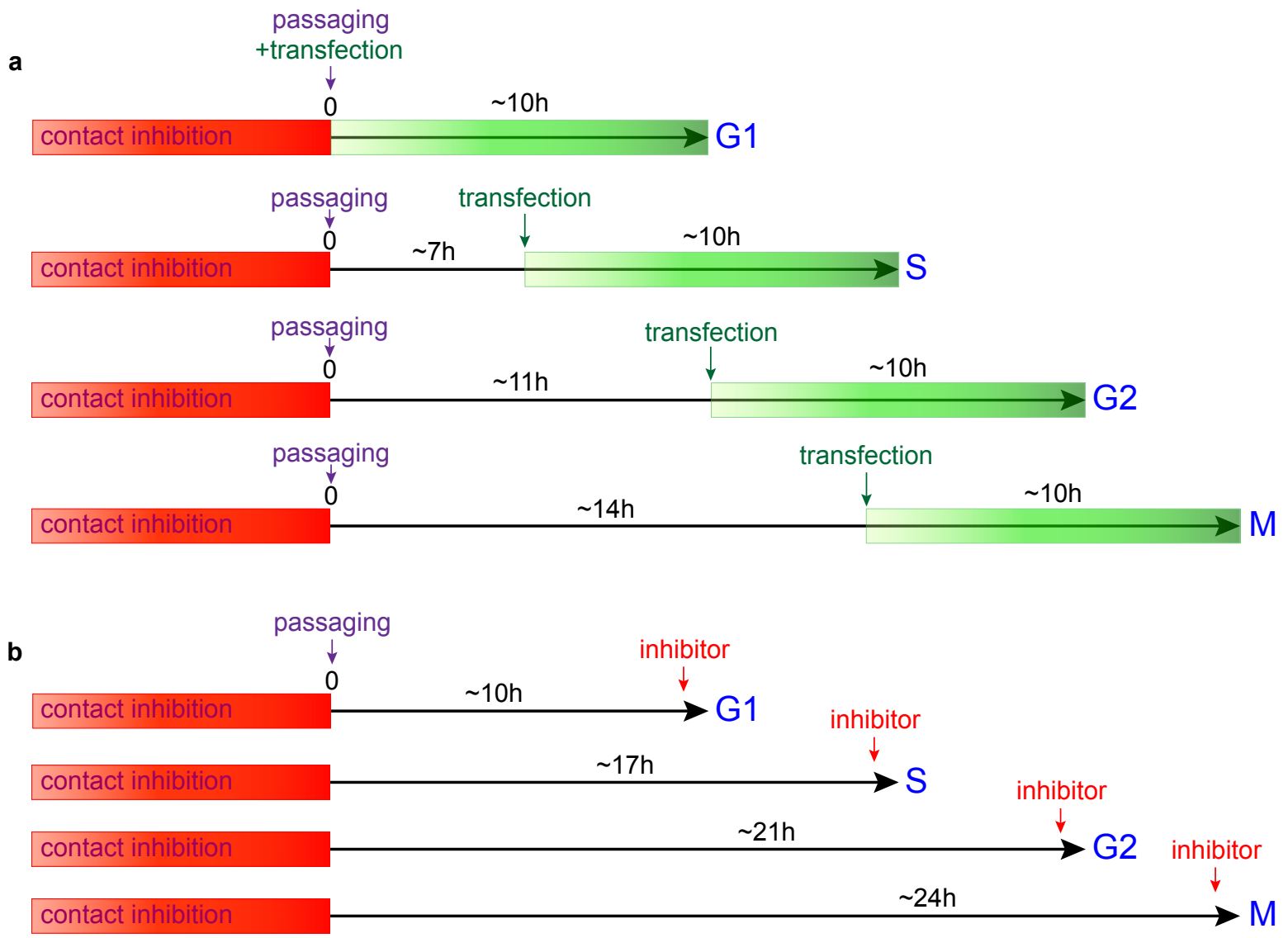

Figure 3 